\title{
Fisiopatología de la COVD-19
}

\author{
Cruz-Durán Alejandro*, Fernández-Garza Nancy Esthela**
}

\begin{tabular}{|c|c|}
\hline 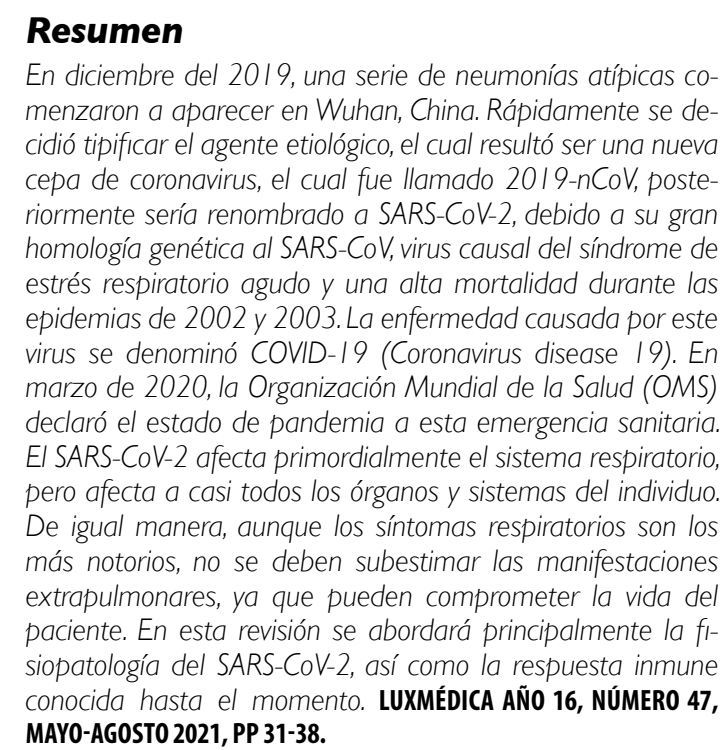 & $\begin{array}{l}\text { Abstract } \\
\text { In December 2019, a series of atypical pneumonia began } \\
\text { to appear in Wuhan, China. It was quickly decided to typify } \\
\text { the etiological agent, which turned out to be a new strain of } \\
\text { coronavirus, which was called } 2019 \text {-nCoV, later it would be } \\
\text { renamed SARS-CoV-2 due to its great genetic homology to } \\
\text { SARS-CoV, the causal virus of the acute respiratory distress } \\
\text { syndrome and high mortality during the } 2002 \text { and } 2003 \text { epi- } \\
\text { demics. The disease caused by this virus was called COVID-I9 } \\
\text { (Coronavirus disease 19). In March 2020, the World Health } \\
\text { Organization (WHO) declared this health emergency a pan- } \\
\text { demic state. SARS-CoV-2 primarily affects the respiratory sys- } \\
\text { tem; however, it also affects almost all organs and systems of } \\
\text { the individual. Similarly, although respiratory symptoms are the } \\
\text { most prominent, extrapulmonary manifestations should not } \\
\text { be underestimated, as they can compromise the patient's life. } \\
\text { This review will mainly address the pathophysiology of SARS- } \\
\text { CoV-2, and the immune response known to date. LUXMÉDICA } \\
\text { AÑ0 16, NÚmERO 47, MAY0-AG0ST0 2021, PP 31-38. }\end{array}$ \\
\hline Palabras clave: coronavirus, COVID-19, & ronavirus, COVID-19, pandemic \\
\hline
\end{tabular}

\section{Introducción}

En diciembre del 2019, una serie de neumonías atípicas comenzaron a aparecer en Wuhan, China. Rápidamente se decidió tipificar el agente etiológico, el cual resultó ser una nueva cepa de coronavirus, el cual fue llamado 2019-nCoV, posteriormente sería renombrado a SARS-CoV-2, debido a su gran homología genética al SARS-CoV, virus causal del síndrome de estrés respiratorio agudo y una alta mortalidad durante las epidemias de 2002 y 2003. La enfermedad

* Estudiante de la Carrera de Médico Cirujano del Centro de Ciencias de la Salud de la Universidad Autónoma de Aguascalientes. Orcid 0000-0002-8952-3398. Correo electrónico: alex 5 a@yahoo.com

** Profesora Investigadora del Departamento de Fisiología. Facultad de Medicina de la Universidad Autónoma de Nuevo León. Orcid 0000-0001-7519-2949. Correo electrónico: nancy-fernandez@live.com.mx

Fecha de recibido: 22 de enero 2021

Fecha de aceptación: 2 de marzo de 2021

Correspondencia: Dra. Nancy Esthela Fernández Garza. Departamento de Fisiología Facultad de Medicina. Universidad Autónoma de Nuevo León. Ave. Gonzalitos 235 Norte. Col. Mitras Centro Código postal 64460. Monterrey, Nuevo León, México. Teléfono 818329 4203. Correo electrónico nancy-fernandez@live.com.mx 
causada por este virus se denominó COVID-19 (Coronavirus disease 19). En marzo de 2020, la Organización Mundial de la Salud (OMS) declaró el estado de pandemia a esta emergencia sanitaria.

Los coronavirus, de la familia Coronaviridae, pertenecen al orden de los Nidovirales, poseen un ácido ribonucleico (RNA) en sentido positivo, no segmentado y de gran tamaño. Se ha visto que infectan el tracto respiratorio, el tracto gastrointestinal y el sistema nervioso. En el ser humano se asocia a enfermedades del tracto respiratorio.

Se reconocen 7 estirpes de coronavirus que infectan al ser humano. Entre éstos, HCoV-229E, HCoV-OC43, HCoV-NL63 y HCoVHKU1, que causan enfermedades leves como el resfriado común y son patógenos frecuentes durante temporadas de bajas temperaturas. Además de éstos, están MERS-CoV, SARS-CoV-1 y SARS-CoV2 , que originan enfermedades más graves y que pueden comprometer la vida del paciente. ${ }^{1,2}$ El SARS-CoV-2 afecta primordialmente el sistema respiratorio, pero afecta a casi todos los órganos y sistemas del individuo. De igual manera, aunque los síntomas respiratorios son los más notorios, no se deben subestimar las manifestaciones extrapulmonares, ya que pueden comprometer la vida del paciente.

En esta revisión, se abordará principalmente la fisiopatología del SARS-CoV-2, así como la respuesta inmune conocida hasta el momento.

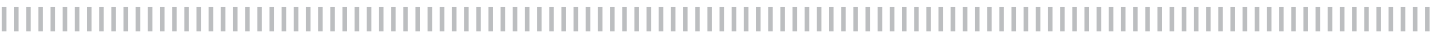

\section{Material y métodos}

Esta revisión de bibliografía se realizó como parte de un proyecto de investigación del XXX Verano de Investigación Científica de la Academia Mexicana de Ciencias.

Para esta revisón bibliográfica se consultaron artículos en el idioma inglés y español de distintas revistas como Elsevier, Nature, JAMA, NEJM, Scielo, con ayuda de buscadores como EBSCO, PubMed y los buscadores nativos de los sitios web de las revistas ya mencionadas. Se tomaron en cuenta artículos desde enero 2020 hasta diciembre 2020. Los principales términos usados para esta búsqueda bibliográfica fueron "COVID-19" y "SARS-CoV-2". Como términos añadidos para búsquedas de cada apartado fueron "inmunology", "neurology", "kidney", "phatophysiology", "gastrointestinal" y "dermatology". Se revisaron 33 artículos en total.

\section{Mecanismo por el cual SARS-CoV-2 invade la célula}

Al inicio de la infección, el SARS-CoV-2 se une a las células del epitelio nasal, del epitelio bronquial y de los neumocitos, por medio de su proteína spike (S) misma que se une al receptor de la enzima convertidora de angiotensina-2 (ACE2). Posteriormente, la serin-proteasa transmembrana tipo 2 (TMPRSS2), expresada en las células del hospedero, facilita la captación mediante adherencia al ACE2 y activa la proteína $S$ de SARS-CoV-2, la cual media la entrada del virus a la célula hospedera. ${ }^{3}$

Las proteínas ACE2 Y TMPRSS2 se expresan en las células del hospedero, principalmente en las células epiteliales alveolares tipo II, células del parénquima pulmonar, endotelio vascular, tejido renal, células pequeñas del intestino, neuronas y glía, entre otras. $^{4,5} \mathrm{Al}$ igual que en otras infecciones 
como la influenza, la infección por SARSCoV-2 causa linfopenia, debido a que infecta a los linfocitos T. Esto se ha observado hasta en un $40 \%$ de los pacientes. ${ }^{3,6}$

Después de que el virus entra a la célula y accede al citosol, inicia la replicación de su genoma de RNA. La replicación codifica dos porciones denominadas marco de lectura abierta (ORF, por sus siglas en inglés open reading frame) que expresan poliproteínas coterminales (pp1a, pp2ab). Para expresar estas proteínas, el virus usa la secuencia (5'UUUAAAC $-3^{\prime}$ ) y un pseudonudo de RNA, a partir del cual el genoma del virus comienza a replicarse. ${ }^{7}$ Después del proceso de replicación y síntesis, las proteínas estructurales $S$, E y $M$ son trasladadas e insertadas en el retículo endoplásmico. Estas proteínas se mueven a través de una vía secretora en el retículo endoplásmico-aparato de Golgi (ERGIC). En este punto, el genoma es encapsulado por la proteína $\mathrm{N}$ dentro de las mebranas ERGIC que contiene los virones maduros. Finalmente, las vesículas con partículas virales se fusionan con la membrana plasmática para liberarlos mediante exocitosis. ${ }^{3,7}$

\section{Respuesta inmunológica}

Al inicio de la infección, las primeras respuestas ante el ingreso y reproducción del virus son mediadas por el sistema inmune innato, dentro del cual participan células dendríticas, linfocitos NK y macrófagos. De igual manera, células no inmunes como células epiteliales y fibroblastos tiene un papel importante. Esta respuesta es iniciada por la detección de patrones moleculares asociados a patógenos (PAMPs, por sus siglas en inglés pathogen-associated molecular patterns) mediante los receptores de reconocimiento ( $P R R$, por sus siglas en inglés, pattern recognition receptor) ubicados tanto en la membrana celular, en endosomas, el citosol y mitocondrias. ${ }^{8}$

EI SARS-CoV-2 es detectado por los receptores TLR3, TLR37 y $\operatorname{TLR}^{9}{ }^{9} \mathrm{y}$, tras activarse, desencadenan una cascada de se- ñales intracelulares que concluye activando factores como NF-kB e interferón (INF), que alteran los mecanismos de defensa celular. Estos factores promueven la síntesis y liberación de citoquinas como la IL-6, TNF- $\alpha$, IL-1ß y la activación de caspasas e INF. Estos últimos actúan sobre el ciclo de multiplicación del virus. Por otra parte, las citoquinas actúan a nivel local y sistémico, generando cambios hemodinámicos y metabólicos que promueven la actividad antimicrobiana. Estas citoquinas al actuar sobre células blanco aumentan la activación del factor de transcripción NK-kB generando una retroalimentación positiva que, de no ser controlada, eventualmente producirá una "tormenta de citoquinas". 8

El INF-1 genera la síntesis de viperina (CIG5), la cual actúa en la producción de proteínas virales en el retículo endoplásmico y su liberación; la MXA actúa formando oligómeros alrededor de partículas virales y también proteínas transmembranales inducidas por interferón (IFITMs, por sus siglas en inglés, interferon-induced transmembrane proteins) que impiden el uso de ribonucleasas por parte del virus. ${ }^{10}$

El proceso infeccioso evoluciona hasta que el virus, así como las células infectadas por éste, sean erradicadas o hasta que el sistema inmune no pueda responder de manera adecuada y se comprometa la vida del paciente. ${ }^{8}$

En caso de que el sistema inmune responda de forma adecuada, el proceso proinflamatorio es frenado por los siguientes mecanismos: la activación de macrófagos 2 y linfocitos T reguladores; la secreción de interleucina 10 (IL-10); el factor de crecimiento endotelial vascular (VEGF, por sus siglas en inglés, vascular endothelial growth factor) y por el factor de crecimiento transformante beta 1 (TGFB, por sus siglas en inglés, transforming growth factor beta). ${ }^{8}$

Por otra parte, la inmunidad adquirida también actúa en el proceso infeccioso. Se han reportado anticuerpos IgM antes de la primera semana de inicio de la infección e 
IgG, linfocitos $\mathrm{T}$ y linfocitos NK contra la proteína $S$ viral, antes del décimo día posterior al inicio de la infección. 8,10,11

\section{Fisiopatología respiratoria}

Una vez en el huésped humano, el virus se adosa a receptores ACE2 que se encuentran ampliamente distribuidos en el epitelio de la faringe, corazón, y en las células caliciformes y células ciliadas del pulmón. Una vez en los alvéolos, el virus se une a los receptores ACE2 de los neumocitos tipo I y II, que ocasiona la activación de los macrófagos y se generan interleucinas (IL) tipo I, 6 y 8, así como el factor de necrosis tumoral alfa (TNF- $\alpha$ ) que a su vez estimulan otros grupos celulares; ${ }^{12}$ como consecuencia, se produce una extravasación vascular, con acúmulo de líquido en el espacio alveolar, atracción de neutrófilos y producción de radicales de oxígeno. Lo anterior se acompaña de la aparición de síntomas como fiebre, tos, disnea, anosmia, entre otros. ${ }^{12,13}$ La tos es producida debido a la estimulación de receptores que corresponden a fibras $C$ que se encuentran en el epitelio de las vías respiratorias. Estos estímulos son dirigidos hacia el sistema nervioso central por el décimo par craneal, y son integrados en el tracto del haz solitario para después ser dirigidos por una vía eferente por el nervio frénico, nervios espinales motores y el décimo por craneal en su porción motora. ${ }^{14}$

La disnea se genera por estímulo de diferentes receptores que transmiten señales de modo excesivo a los centros respiratorios de la médula oblongada y el puente, y desde ahí son enviados a la corteza cerebral. Estos receptores son: receptores al estiramiento de la pequeña vía aérea, que se estimulan con la insuflación pulmonar; receptores de gases o partículas, y receptores J sensibles a la distensión y congestión de los vasos pulmonares. ${ }^{14}$ En las afecciones pulmonares como la neumonía causada por SARSCoV-2 en donde se ve alterada la hematosis y se genera hipoxemia, se estimulan los quimiorreceptores centrales y periféricos, que a su vez envían señales al centro respiratorio para aumentar la ventilación pulmonar, esto genera una mayor actividad de los músculos respiratorios, lo cual genera sensación de disnea. Además, el edema pulmonar produce estimulación de los receptores J que también contribuyen a provocar la sensación de disnea. ${ }^{15}$

En relación con la fiebre, se reporta mayor frecuencia de cuadro febril leve y moderado, y fiebre alta sólo en casos aislados, con duración entre 1 a 9 días. $^{12}$ La gran cascada de citoquinas producida por la respuesta inmunológica a la infección de SARS-CoV-2, en especial las interleuquinas 1- $\alpha, 1-\beta, 6,18$, factor de necrosis tumoral alfa (TNF- $\alpha$ ) y algunos interferones, actúa sobre el sistema nervioso central (SNC) al ser reconocida por las células endoteliales del órgano vasculosum de la lámina terminalis (OVLT) los cuales inducen la expresión de la enzima ciclooxigenasa 2 y prostaglandina E2 (PGE2). ${ }^{14}$

La PGE2, promueve la liberación del adenosín monofosfato cíclico (AMPc) en la glia del hipotálamo. El AMPc actúa como neurotransmisor y genera una disminución de la actividad de neuronas preópticas sensibles a temperaturas elevadas y estimula neuronas sensibles a temperaturas bajas. Este fenómeno genera que se activen mecanismos de producción y conservación del calor, tales como la fiebre..$^{12,15} \mathrm{El}$ contacto de las neuronas olfatorias con el epitelio nasal es muy íntimo, por lo cual no es extraño que SARS-CoV-2 pueda infectar a estas células. Además, es bien conocido que algunas especies de coronavirus como SARS-CoV-1 tienen tropismo por las neuronas olfatorias porque presentan el receptor ACE2, el cual forma parte importante en su rol de neuroregeneración. Inclusive, se ha observado que los coronavirus usan esta vía para llegar al SNC. Al infectar las neuronas olfatorias y usar su maquinaria para replicación, impiden que estas envíen impulsos nerviosos $y$, en consecuencia, se manifiesta a través de hiposmia o anosmia. ${ }^{16}$ 


\section{Fisiopatología gastrointestinal}

A pesar de que no hay una respuesta clara del tropismo de SARS-CoV-2 hacia el epitelio del tracto digestivo, se ha observado que éste expresa la enzima ACE2, por tal motivo, SARS-CoV-2 puede usar esta enzima como receptor e infectar dichas células. Esto ayuda a la evidencia de la presencia y replicación del virus SARS-CoV-2 en el epitelio gastrointestinal, siendo menor la expresión del receptor ACE2 en el epitelio esofágico, pero es alto en el gástrico, duodeno e íleo, recto y colangiocito del tejido hepático. Además de la expresión del receptor ACE2, las células del epitelio intestinal también expresan el receptor TMPRSS2. La sintomatología gastrointestinal asociada con la infección por SARS-CoV-2 es diarrea, náusea, vómito y dolor abdominal.4,17,18 La infección de las células del intestino por parte de SARS-CoV-2 produce una inflamación del tejido, liberando gran cantidad de citoquinas, entre ellas: leucotrienos, prostaglandinas e histamina. Por lo tanto, se genera una extravasación de neutrófilos y edema tisular. Debido a esto, se genera un desequilibrio entre la absorción y secreción del tejido gastrointestinal, manifestándose como diarrea. ${ }^{17}$

Este mismo mecanismo que genera citoquinas e inflamación, estimula regiones del sistema nervioso, tales como la zona de quimiorreceptores gatillo y el tracto del haz solitario. La zona de quimiorreceptores gatillo es sensible a la dopamina, opioides y serotonina. Por otra parte, el tracto del haz solitario es sensible hacia la encefalina, histamina y adrenérgicos, entre otros. Al estimular dichos centros neurológicos, éstos reenvían un impulso al centro del vómito, el cual activa vías eferentes del nervio frénico, el nervio vago y nervios espinales para generar contracciones de la musculatura abdominal y producir emesis. ${ }^{19}$ Debido al proceso inflamatorio, se estimulan los receptores sensibles al estiramiento de las vísceras huecas como es el intestino delgado. Este estímulo viaja por el sistema nervioso simpático hacia la médula espinal y posteriormente hacia la corteza cerebral para ser interpretado como dolor visceral. ${ }^{15}$

\section{Afectación hepática y pancreática}

Por el momento, no se conoce con exactitud los mecanismos de lesión hepática y pancreática. Aun así, se han reportado en múltiples revisiones alteraciones en los perfiles bioquímicos tanto hepático como pancreático y se ha asociado con una mayor letalidad. ${ }^{17}$

Es probable que el daño hepático sea ocasionado por la lesión directa del virus debido a su tropismo por los receptores ACE2 presentes en el tejido hepático. Otro mecanismo que explica la lesión hepática es el uso de medicamentos a dosis altas en estos pacientes. ${ }^{20}$ De igual manera que en la lesión hepática, se puede observar inflamación pancreática manifestada bioquímicamente con un aumento de la lipasa y amilasa séricas. ${ }^{17}$

\section{Fisiopatología cardiovascular}

Las manifestaciones cardiovasculares asociadas a la infección por SARS-CoV-2 son principalmente de origen tromboembólico y asociadas a un estado de hipercoagulabilidad. La más común es la tromboembolia pulmonar, reportada con una incidencia del $25 \%$ en pacientes con enfermedad crítica. ${ }^{21}$ Por otra parte, los eventos trombóticos arteriales tienen menos incidencia. Entre éstos se encuentran el infarto agudo al miocardio, eventos vasculares cerebrales, trombosis microvascular que puede afectar cualquier región del organismo. ${ }^{21}$

Los mecanismos fisiopatológicos asociados a trombosis en pacientes en estado crítico suelen ser ocasionados por la inmovilización, la ventilación mecánica, los accesos venosos centrales y las deficiencias nutriciones, pero el principal causante está asociado al estado proinflamatorio y tormenta de citoquinas vinculada a esta enfermedad. ${ }^{21}$ Los análisis de laboratorio de estos pacientes suelen mostrar elevaciones de la 
proteína $C$ reactiva, del dímero $D$, fibrinógeno, factor VIII, factor de von Willebrand e IL-6; por otra parte, existe un descenso de la antitrombina. ${ }^{9}$ Los trombos en el sistema venoso son ocasionados por la lesión directa del endotelio por el virus, aunado por la estasis sanguínea asociada a la inmovilización, y el estado proinflamatorio, por la tormenta de citoquinas en respuesta a la infección por SARS-CoV-2. 3,15

\section{Fisiopatología neurológica}

Las manifestaciones neurológicas asociadas a la infección por SARS-CoV-2 se pueden clasificar en tres: a. Manifestaciones del SNC como cefalea, pérdida de la conciencia, eventos vasculares isquémicos y ataxia; $b$. Manifestaciones nerviosas periféricas, como la pérdida del gusto, del olfato, de la visión y neuropatías periféricas; y, c. Manifestaciones músculo esqueléticas. ${ }^{22}$

Hay varias rutas por las cuales el SARSCoV-2 invade el SNC, una de ellas es que la infección puede darse por transporte retrógrado axonal desde el epitelio olfatorio, debido a la posibilidad de diseminación viral desde este epitelio a través de los nervios craneales, como el olfatorio, trigémino, glosofaríngeo y vago. Se postula que hay otras rutas de la invasión viral, ya sea por el sistema nervioso entérico o ruta hematógena. ${ }^{20}$ Está claro que el daño al sistema nervioso es mediado por la lesión directa de neuronas y células gliales al ser infectadas, del mismo modo que la inflamación sistémica y del tejido nervioso generan el daño. ${ }^{23}$

Por otra parte, las manifestaciones neurológicas pueden deberse a la extensa desregulación de la homeostasis de todos los sistemas del organismo involucrados en la infección, por ejemplo: falla orgánica múltiple, infartos al miocardio, choque, arritmias y falla renal. Todas estas entidades conllevan a una hipoxia e hipercoagulabilidad secundaria que puede generar daños en el sistema nervioso sin necesidad de que exista una invasión directa del virus al tejido ner- vioso. ${ }^{23}$ Como en otras infecciones de carácter viral, también se ha asociado la infección por SARS-CoV-2 al desarrollo posterior de síndrome de Guillain-Barré. ${ }^{24,25}$

\section{Fisiopatología renal}

La entidad patológica renal en estos pacientes suele manifestarse como lesión renal aguda en aquellos pacientes en estado crítico de la enfermedad. Los estudios de laboratorio muestran hematuria y proteinuria. Además, la presencia de lesión renal aguda está asociada a una mayor mortalidad. Las causas por las que se genera la lesión renal aguda son multifactoriales, y se ha involucrado a factores como la hipoxia sistémica, eventos vasculares en los trombocitos, la tormenta de citoquinas y lesión directa al tejido renal. ${ }^{26,27}$

La lesión directa se debe a la presencia del receptor ACE2 en el tejido renal, que es inclusive cien veces más que el tejido pulmonar y afecta primordialmente a las células del túbulo contorneado proximal, por lo que sus funciones de reabsorción y secreción se ven alteradas, provocando un acúmulo de urea y creatinina en el organismo. ${ }^{28,29}$

Los pacientes que presentan este cuadro llegan a necesitar terapia de reemplazo renal debido a la lesión renal aguda. ${ }^{30}$

\section{Fisiopatología cutánea}

Las manifestaciones cutáneas no suelen ser la causa que compromete la vida del paciente y su fisiopatología es aún incierta. La incidencia de estas entidades no está bien establecida; sin embargo, se ha reportado gran variedad de manifestaciones cutáneas en los pacientes infectados por SARS-CoV-2. ${ }^{31}$ Entre las manifestaciones más comúnmente encontradas en pacientes adultos son lesiones vesiculares, urticaria, erupciones maculopapulares y necrosis. Otras manifestaciones reportadas con menor frecuencia son erupciones papulomatosas, eritema multiforme y petequias. ${ }^{32,33}$ Por 
otra parte, en los pacientes pediátricos estas manifestaciones suelen ocurrir hasta en un tratamiento y no son indicativo de gravedad $20 \%$ lesiones papulosas. Suelen mejorar sin

\section{de la enfermedad. ${ }^{31}$}

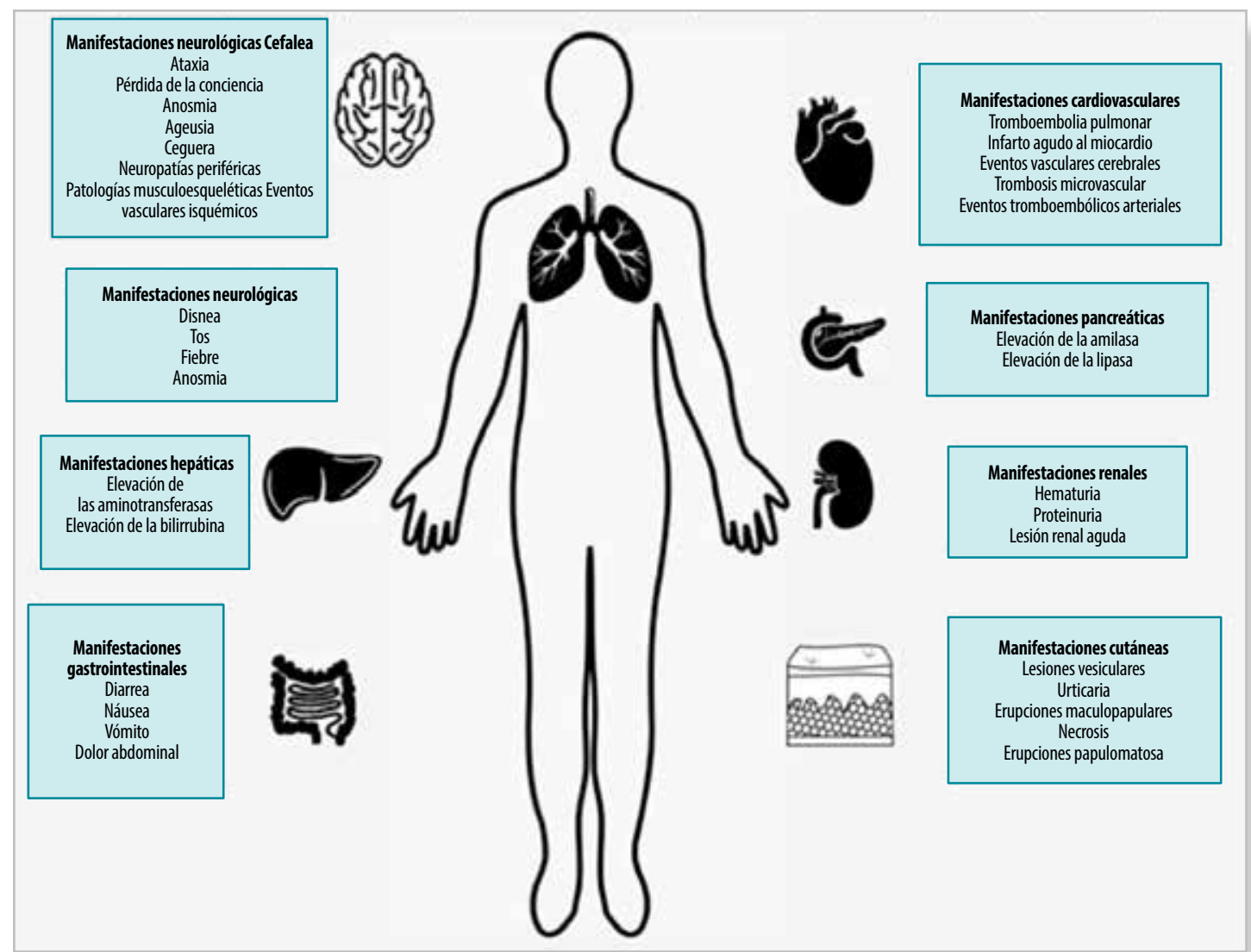

Figura 1. Esquema de la fisiopatología por la infección del coronavirus SARS-CoV-2

\section{Conclusiones}

La infección por SARS-CoV-2 es una entidad que involucra a todo el organismo. Aunque las afecciones respiratorias son las más notorias y están asociadas a complicaciones y al riesgo de mortalidad, las lesiones extrapulmonares también comprometen la vida del paciente en gran medida. El conocimiento de la fisiopatología de esta enfermedad está en continuo desarrollo. Aun así, es importante continuar clarificándola, ya que se puede comprender de manera más amplia no sólo el desarrollo de la enfermedad y su historia natural, sino también su sintomatología, pronóstico y tratamiento.

\section{Bibliografía}

1. Monroy-Gómez J, Torres-Fernández O. Efectos de los coronavirus del síndrome respiratorio agudo grave (SARS-
(oV) y del síndrome respiratorio del Medio Oriente (MERS-CoV) en el sistema nervioso. ¿Qué esperar del SARS-CoV-2? Biomédica. 2020;40(2):173-179.

2. Sequera G. SARS-Cov 2, un virus para reumatólogos. 
?Rev. parag. reumatol. 2020;6(2):48-49.

3. Wiersinga WJ, Rhodes A, Cheng AC, Peacock SJ, Prescott HC. Pathophysiology, Transmission, Diagnosis, and Treatment of Coronavirus Disease 2019 (COVID-19): A Review. JAMA J Am Med Assoc. 2020;324(8):782-93.

4. Gupta A, Madhavan M V., Sehgal K, Nair N, Mahajan S, Sehrawat TS, et al. Extrapulmonary manifestations of COVID-19. Nat Med . 2020;26:1017-32.

5. Villapol S. Gastrointestinal symptoms associated with COVID-19: impact on the gut microbiome. Transl Res . 2020;226:57-69.

6. Ghomi $R$, Asgari $N$, Hajiheydari $A$, Esteki $R$, Biyabanaki F, Nasirinasab F. The COVID-19 pandemic: a systematic review of the current evidence. Russ J Infect Immun. 2020;10(4):655-663.

7. Balakrishnan a. A review on pandemic disease covid-19: structure, pathophysiology, epidemiology and treatment. Journal of Advanced Scientific Research. 2012;1(2):19-23.

8. Mateos, Edgard Alexis. Armando el Rompecabezas Fisiopatológico del COVID-19 El Patógeno y la Respuesta Inmune. EFACIM. 2020;53(2):105-126.

9. Espinosa Rosales Francisco Javier. Inmunopatología de la infección por virus SARS-CoV-2. Acta Pediátr Méx. 2020;41(1):S42-S50.

10. García-Salido A. Narrative review of the immune response against coronavirus: An overview, applicability for SARS-COV-2, and therapeutic implications. An Pediatr. 2020;93(1):60.e1-60.e7

11. Parra Izquierdo V, Florez-Sarmiento C, Romero-Sanchez MC. Inducción de "tormenta de citocinas" en pacientes infectados con SARS- CoV-2 y desarrollo de COVID-19. ¿Tiene el tracto gastrointestinal alguna relación en la gravedad? Rev Colomb Gastroenterol. 2020;35(Supl.1):2129

12. Verónica Martínez, Isabel Tovar, MA villarroel. Covid-19 Y Afectacion Pulmonar. Venez Pueric y Pediatría. 2020;83(2):25-30

13. Sneha Ambwani, Arup Kumar Misra RK. Lung pathology in COVID 19: A ststematic review. Int J Appl Basic Med Res. 2017;2019(November):193-195.

14. Jofré DP, García KC. Tos en otorrinolaringología: Revisión actualizada del enfoque clínico. Rev Otorrinolaringol y cirugía cabeza y cuello. 2017;77(4):456-466.

15. Horacio. A. Argente, Marcelo E. Álvarez. Semiología médica. 2a eición. Buenos aires, Argentina: Editorial Médica Panamericana; 2016.

16. Gengler I, Wang JC, Speth MM, Sedaghat AR. Sinonasal pathophysiology of SARS?CoV ?2 and COVID ?19: A systematic review of the current evidence . Laryngoscope Investig Otolaryngol. 2020;5(3):354-359.

17. Fuentes Díaz CF, Zabaleta Taboada OY. Manifestaciones gastrointestinales de la infección por el "Nuevo Coronavirus." Rev Colomb Gastroenterol. 2020;35(Supl.1):69-72.

18. Dianora Navarro, Nina Colina, Karolina López, G Daoud. Afectación Gastrointestinal y Covid 19. Venez Pueric y Pediatría. 2020;83(2):31-38
19. David A Rincón, J. Francisco Valero. Prevención de la náusea y el vómito postoperatorios. Col anest. 2007;35:293300.

20. Patel KP, Patel PA, Vunnam RR, Hewlett $A T$, Jain $R$, Jing $R$, et al. Gastrointestinal, hepatobiliary, and pancreatic manifestations of COVID-19. J Clin Virol. 2020;128(April):104386.

21. Abou-Ismail MY, Diamond A, Kapoor S, Arafah Y, Nayak L. The hypercoagulable state in COVID-19: Incidence, pathophysiology, and management. Thromb Res. 2020;194(May):101-115.

22. Vonck K, Garrez I, De Herdt V, Hemelsoet D, Laureys G, Raedt R, Boon P. Neurological manifestations and neuroinvasive mechanisms of the severe acute respiratory syndrome coronavirus type 2. Eur J Neurol. 2020;27:15781587.

23. Martínez HR, Figueroa-Sánchez JA, Castilleja-Leal F, Martínez-Reséndez MF, Ferrigno AS. The underrated nervous system involvement by COVID-19. Rev Mex Neurocienc. 2020;21(4):2-7.

24. Munhoz RP, Pedroso JL, Nascimento FA, De Almeida SM Barsottini OGP, Cardoso FEC, Teive HAG. Neurological complications in patients with SARS-CoV-2 infection: A systematic review. Arq Neuropsiquiatr. 2020;78(5):290300.

25. Nath A, Smith B. Neurological complications of COVID-19: From bridesmaid to bride. Arq Neuropsiquiatr. 2020;78(8):459-460.

26. Moitinho MS, Belasco AG da S, Barbosa DA, Fonseca CD da. Acute Kidney Injury by SARS-CoV-2 virus in patients with COVID-19: an integrative review. Rev Bras Enferm. 2020;73 2(Suppl 2):e20200354.

27. Post A, den Deurwaarder ESG, Bakker SJL, de Haas RJ, van Meurs M, Gansevoort RT, et al. Kidney Infarction in Patients With COVID-19. Am J Kidney Dis. 2020;76(3):431435.

28. Zheng $X$, Zhao $Y$, Yang L. Acute Kidney Injury in COVID-19: The Chinese Experience. Semin Nephrol. 2020;2019(8):430-442.

29. Jesus O, Machado J, Carvalho I De, Andreon FM. Acute kidney injury in SARS-COV-2 infection. 2020;(October):157-159.

30. Duarte PMA, Batos Filho FAG, Duarte JVA, Duarte BA, Duarte IA, Lemes RPG, Duarte FB. Renal changes in COVID-19 infection. Rev Assoc Med Bras. 2020;60(10):13351337.

31. Granados Campos L, Broche del Pino L, Pérez Leal L, López Rodríguez VM. Manifestaciones cutáneas en pacientes pediátricos infectados por el coronavirus SARS-CoV-2. Rev Cubana Pediatr. 2020;92:1-14.

32. Feldman S, Freeman E. Coronavirus disease 2019 (COVID-19): Cutaneous manifestations and issues related to dermatologic care. UpToDate. 2020;2019:1-24.

33. Lavery MJ, Bouvier CA, Thompson B. Cutaneous manifestations of COVID-19 in children (and adults): A virus that does not discriminate. Clin Dermatol. 2020;14 (40)1-6. 